\title{
Extensão acadêmica como ferramenta de prática educativa no processo de formação de enfermeiros
}

\author{
Academic extension as a tool of educational practice in the process of training nurses \\ La extensión académica como herramienta de práctica educativa en el proceso de la educación en \\ enfermeira
}

Recebido: 07/06/2021 | Revisado: 14/06/2021 | Aceito: 18/06/2021 | Publicado: 02/07/2021

\author{
Izadora Nunes da Silva \\ ORCID: https://orcid.org/0000-0001-6302-6310 \\ Centro Universitário Mario Pontes Jucá, Brasil \\ E-mail: Izadoranunes19.in@gmail.com \\ Gláucia dos Santos Silva \\ ORCID: https://orcid.org/0000-0002-7235-8146 \\ Centro Universitário Mario Pontes Jucá, Brasil \\ E-mail: silva11glaucia@gmail.com \\ Vanessa Maria do Nascimento \\ ORCID: https://orcid.org/0000-0003-1418-1001 \\ Centro Universitário Mario Pontes Jucá, Brasil \\ E-mail: nascimentvanessa97@gmail.com \\ Juliana Peixoto Teixeira da Silva \\ ORCID: https://orcid.org/0000-0003-1329-3386 \\ Centro Universitário Mario Pontes Jucá, Brasil \\ E-mail: Peixoto99@live.com \\ Amauri dos Santos Araújo \\ ORCID: https://orcid.org/0000-0001-7435-5670 \\ Centro Universitário Mario Pontes Jucá, Brasil \\ E-mail: amauriaraujo.sms@gmail.com \\ Raquel Ferreira Lopes \\ ORCID: https://orcid.org/0000-0002-2061-7038 \\ Centro Universitário Mario Pontes Jucá, Brasil \\ E-mail: raquelloppes@gmail.com
}

\begin{abstract}
Resumo
Objetivo: discutir a importância da extensão universitária no processo de formação do profissional do enfermeiro a partir de um relato de experiência de acadêmicos de um curso de bacharelado em enfermagem. Consiste em um estudo descritivo de abordagem qualitativa do tipo relato de experiência, construído por meio de uma análise críticoreflexiva, mediante as experiências vivenciadas sobre as atividades desenvolvidas do Projeto de Extensão Educação em Saúde (PROES) de um centro universitário da rede privada de Maceió, Alagoas. As atividades desenvolvidas pelo projeto se baseavam em palestras, rodas de conversas, encontros lúdicos sobre assuntos envolvendo a promoção em saúde para o público infantil, adolescente e adultos, sendo realizadas durante o ano de 2019 a 2020, uma vez por mês, tendo como campo de atuação uma unidade de saúde e duas escolas. Observa-se a importância da extensão universitária no processo de formação do enfermeiro, haja visto que as contribuições da prática extra-acadêmica trazem benefícios não apenas para comunidade, mas para os acadêmicos de enfermagem, como apresentadas neste relato, em destaque para a interação entre a pesquisa-ensino-extensão, relação teoria com a prática, produção de aprendizagem, aquisição de habilidades e competências, autonomia, formulação de pensamento crítico e reflexivo para resolução situações/problemas reais. Em suma, evidencia-se a relevância de atividades de extensão durante a graduação visto que esse processo favorece o desenvolvimento e o fortalecimento de práticas educativas, do raciocínio investigativo e a disseminação de conhecimentos associados a realidade vivenciada, bem como a estimulação pela pesquisa embasada em evidências científicas, contribuindo para a construção de uma postura profissional, ética e humanizada frente a área escolhida.
\end{abstract}

Palavras-chave: Educação em saúde; Estudantes de enfermagem; Relações comunidade-instituição; Projetos de pesquisa.

\footnotetext{
Abstract

Objective: to discuss the importance of university extension in the process of training the nursing professional, based on an experience report of students from a baccalaureate nursing course. It consists of a descriptive study of qualitative approach of the experience report type, built by means of a critical-reflexive analysis, through the experiences lived on the activities developed by the Education in Health Extension Project (PROES) of a private
} 
university center in Maceió, Alagoas. The activities developed by the project were based on lectures, conversation circles, and playful meetings about issues involving health promotion for children, adolescents, and adults, being held during the year 2019 to 2020 , once a month, having as field of action a health unit and two schools. It is observed the importance of university extension in the nursing education process, given that the contributions of extra-academic practice bring benefits not only for the community, but also for nursing students, as presented in this report, especially the interaction between research-teaching-extension, theory-practice relationship, production of learning, acquisition of skills and competencies, autonomy, formulation of critical and reflective thinking to solve real situations/problems. In short, it is evident the relevance of extension activities during graduation since this process favors the development and strengthening of educational practices, of investigative reasoning and the dissemination of knowledge associated with the reality experienced, as well as the stimulation for research based on scientific evidence, contributing to the construction of a professional, ethical and humanized attitude towards the chosen area.

Keywords: Health education; Students nursing; Community-institutional relations; Research design.

\section{Resumen}

Informar de la experiencia de los estudiantes de enfermería de grado sobre la importancia de la extensión universitaria en el proceso de formación de enfermería. Consiste en un estudio descriptivo de enfoque cualitativo del tipo informe de experiencia, construido a través de un análisis crítico-reflexivo, a través de las experiencias de las actividades desarrolladas en el Proyecto de Extensión en Salud (PROES) de un centro universitario privado en Maceió, Alagoas. Se observa la importancia de la extensión universitaria en el proceso educativo de la enfermería, dado que los aportes de la práctica extra-académica traen beneficios no sólo para la comunidad, sino también para los estudiantes de enfermería, como se presenta en este informe, especialmente la interacción entre investigación-enseñanza-extensión, relación teoría-práctica, producción de aprendizajes, adquisición de habilidades y competencias, autonomía, formulación de pensamiento crítico y reflexivo para resolver situaciones/problemas reales. En definitiva, es evidente la relevancia de las actividades de extensión durante la graduación ya que este proceso favorece el desarrollo y fortalecimiento de las prácticas educativas, el razonamiento investigativo y la difusión de conocimientos asociados a la realidad vivida, así como el estímulo para la investigación basada en la evidencia científica, contribuyendo a la construcción de una actitud profesional, ética y humanizada hacia el área elegida.

Palabras clave: Educación en salud; Estudiantes de enfermería; Relaciones comunidad-institución; Proyectos de investigación.

\section{Introdução}

A promoção em saúde representa uma forte proposta de empoderamento do indivíduo/comunidade, por meio da prática do autocuidado e a viabilização da participação efetiva destes sobre a atenção à saúde. O que leva ao reconhecimento das necessidades e através do pensamento crítico, estimula o indivíduo a adotar estratégias transformadoras e emancipadoras voltadas para o próprio bem-estar. Assim, ao se pensar nessa promoção como instrumento de acolhimento e processo político pedagógico, se permite compreender a importância desta e da sua implementação dentro dos diferentes cenários, pelos profissionais da saúde, em especial da Enfermagem, haja visto que esta tem como eixo norteador a promoção do cuidado (Rios, Sousa \& Caputo, 2019; Backes et al., 2018).

Partindo do pressuposto de que a Enfermagem potencializa suas atividades assistenciais movida pela atenção ao indivíduo sadio ou doente de forma holística e humanizada, assim como pelo cuidado sistematizado, a promoção em saúde faz parte das atribuições e do papel desta profissão dentro do processo do cuidado. Além disso, há, no desenvolvimento do trabalho da Enfermagem as atividades de educação em saúde e prevenção de doenças, observando assim a amplitude que esta área alcança. Nessa dialética, evidencia-se que a promoção em saúde na enfermagem não é apenas uma ferramenta, mas um pilar norteador ligado intimamente à função do enfermeiro em toda a sua prática (Lima, 2018; Janini, Bessler \& Vargas 2015).

Observa-se então, que a enfermagem é a peça principal para o desenvolvimento promoção em saúde por meio de atividades educativas que visam a propagação de informações de saúde, construção de conhecimentos, estimulação e adoção de hábitos saudáveis e a implementação de estratégias para o autocuidado. Uma vez que através do olhar holístico, escuta ativa e do acolhimento proporcionam a identificação das necessidades da comunidade/indivíduo, permitindo assim o diagnóstico e o reconhecimento de determinantes sociais e a possibilidade de atuação sobre eles, além de inserir comunidade/indivíduo no processo de cuidado e atenção à saúde (Backes et al., 2018; Ferreira, 2018). 
Para tanto, na prática, observa-se a importância do desenvolvimento da promoção em saúde pelos profissionais da enfermagem, assim como a relevância de incluir a temática na graduação, possibilitando ao acadêmico a compreensão da amplitude do cuidar e a promoção da saúde dentro dos diversos contextos sociais, políticos e culturais, e com isso potencializando seus conhecimentos e adquirindo vivências ainda na sua formação. Nesta perspectiva, diversas são as práticas educativas existentes nos cursos de enfermagem, que permitem a atuação do acadêmico nas situações reais e a criação de ações educativas frente a promoção em saúde, dentre elas, a extensão acadêmica (Costa, et al., 2020; Palheta et al., 2020; Lima, 2018).

A extensão acadêmica voltada para a promoção em saúde é um mecanismo que desempenha um grande papel no desenvolvimento crítico e reflexivo do estudante, ao possibilitar a articulação de ações e atividades educativas de acordo com a necessidade de cada indivíduo, favorecendo o elo entre a díade acadêmicos e os usuários. Assim, a participação do graduando de enfermagem nas realizações das atividades extensionistas possibilita uma formação articulada com as vivências e experiências, o desenvolvimento de uma escuta sensível e uma visão holística frente o cuidado, bem como, a diversificação dos ambientes, compreendendo os diferentes campos de atuação do enfermeiro (Mendes, Fernandez \& Sacardo, 2016; Costa et al., 2015).

Baseado nesta premissa, o principal foco que direciona esse estudo são as ações e atividades educativas implementadas em diferentes cenários através do Projeto de Extensão Educação em Saúde (PROES), desenvolvido por um grupo de acadêmicas de Enfermagem de um Centro Universitário da rede privada de educação localizado no município de Maceió, Alagoas. Cuja proposta foi abordar temáticas condizentes com as necessidades da comunidade/indivíduo, buscando mediar informações e orientações sobre o autocuidado e atenção à saúde, por meio de diversas estratégias educativas e abordagens sistêmicas, para o público em geral em diferentes espaços sociais.

Assim, o presente estudo trata como objeto a extensão acadêmica como ferramenta de prática educativa no processo de formação de enfermeiros, tendo em vista que as vivências durante o desenvolvimento do projeto ofereceram contribuições significativas na exploração de temas vinculados para a área de formação, além do aprimoramento de habilidades e competências frente a promoção da saúde. Desta forma, a motivação em realizar este estudo se deu na necessidade de evidenciar a importância da extensão como ferramenta indispensável na formação do enfermeiro, bem como na sua prática com a comunidade.

Neste debate, toma-se a educação em saúde como temática de interesse, e com isso, a extensão enquanto um fator influenciador e potencializador na formação do enfermeiro como uma ferramenta promotora da prática reflexiva, este estudo pretende responder ao seguinte questionamento: "Qual a importância da extensão universitária no processo de formação do profissional enfermeiro?". Diante o exposto, emerge o objetivo desse estudo: Discutir a importância da extensão universitária no processo de formação do profissional enfermeiro a partir de um relato de experiência de acadêmicos de um curso de bacharelado em enfermagem.

\section{Metodologia}

Este artigo consiste em um estudo descritivo de abordagem qualitativa do tipo relato de experiência, construído por meio de uma análise crítico-reflexiva, mediante as experiências vivenciadas sobre as atividades desenvolvidas do Projeto de Extensão Educação em Saúde (PROES). Compreende-se que o relato de experiência é um estudo produzido a partir das vivências/situações de algum fato específico e relevante para área de atuação cuja prática relaciona-se com a teoria estudada possibilitando a aquisição de habilidades e o aprimoramento de conhecimentos teórico-práticos (Daltro \& Faria, 2019).

O PROES foi criado por um grupo de 6 (seis) acadêmicas do curso de bacharelado em Enfermagem do Centro Universitário Mário Pontes Jucá (UMJ), localizado no município de Maceió, estado de Alagoas, em maio de 2019, possuindo 
duração total de 1 (um) ano. A finalidade do projeto era o empoderamento e a participação do indivíduo/sociedade como principal protagonista da atenção à saúde, envolvendo assim toda a população na operacionalização do autocuidado e não focando apenas em grupos de riscos para doenças, bem como promover ainda na graduação, a atuação dos acadêmicos de Enfermagem em contextos reais de trabalho.

As ações educativas foram desenvolvidas com uma frequência mensal, tendo como principal campo de atuação uma unidade de saúde localizada no bairro Santos Dumont em Maceió e duas escolas públicas, sendo uma da rede municipal localizada no bairro Barro Duro e a outra da rede estadual localizada no bairro Cidade Universitária, ambas em Maceió. As temáticas foram divididas conforme público-alvo, abrangendo crianças, adolescentes, adultos jovens e idosos. As temáticas discutidas no geral correspondiam às orientações e mediação de informações relevantes acerca do autocuidado frente a higienização, alimentação, realização de atividades físicas e as doenças crônicas em especial diabetes e hipertensão, além de abordagens sobre educação sexual e reprodutiva, saúde do homem e da mulher como evidencia o Quadro 1.

Quadro 1 - Organização das ações educativas do projeto de extensão PROES durante 2019 a 2020. Maceió, 2021.

\begin{tabular}{|c|c|c|c|c|c|}
\hline PERÍODO & TEMA ABORDADO & LOCAL & PÚBLICO & DURAÇÃO & 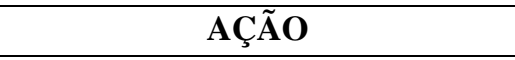 \\
\hline $\begin{array}{l}\text { Junho } \\
(2019)\end{array}$ & $\begin{array}{l}\text { Câncer de colo de } \\
\text { útero: importância do } \\
\text { exame citopatológico }\end{array}$ & $\begin{array}{l}\text { Unidade de } \\
\text { Saúde }\end{array}$ & $\begin{array}{l}\text { Adulto/idoso } \\
\text { (mulheres) }\end{array}$ & $\begin{array}{l}1 \text { hora e } 30 \\
\text { minutos }\end{array}$ & $\begin{array}{l}\text { Roda de conversa com bate-papo } \\
\text { dinâmico }\end{array}$ \\
\hline $\begin{array}{l}\text { Julho } \\
(2019)\end{array}$ & $\begin{array}{l}\text { Infecções sexualmente } \\
\text { Transmissíveis: o que } \\
\text { sabem os adolescentes }\end{array}$ & $\begin{array}{l}\text { Escola } \\
\text { Estadual }\end{array}$ & Adolescentes & 2 horas & $\begin{array}{l}\text { Bate-papo dinâmico com material } \\
\text { expositivo (cartazes expositivos e } \\
\text { slide) e dinâmica "mito ou verdade" }\end{array}$ \\
\hline $\begin{array}{l}\text { Agosto } \\
(2019)\end{array}$ & $\begin{array}{l}\text { Hipertensão e diabetes } \\
\text { mellitus: prevenção e } \\
\text { cuidados }\end{array}$ & $\begin{array}{l}\text { Unidade de } \\
\text { Saúde }\end{array}$ & Adulto/idoso & $\begin{array}{l}1 \text { hora e } 30 \\
\text { minutos }\end{array}$ & $\begin{array}{l}\text { Roda de conversa com exposição } \\
\text { de material lúdico }\end{array}$ \\
\hline $\begin{array}{l}\text { Setembro } \\
(2019) \\
\end{array}$ & $\begin{array}{l}\text { Alimentação saudável } \\
\text { no espaço escolar }\end{array}$ & $\begin{array}{l}\text { Escola } \\
\text { Municipal }\end{array}$ & Crianças & 2 horas & $\begin{array}{l}\text { Utilização de fantoches (peça } \\
\text { teatral) }\end{array}$ \\
\hline $\begin{array}{l}\text { Outubro } \\
(2019)\end{array}$ & Câncer de mama & $\begin{array}{l}\text { Unidade de } \\
\text { Saúde }\end{array}$ & $\begin{array}{l}\text { Adulto/idoso } \\
\text { (mulheres) }\end{array}$ & $\begin{array}{l}1 \text { hora e } 30 \\
\text { minutos }\end{array}$ & $\begin{array}{l}\text { Roda de conversa com bate-papo } \\
\text { dinâmico e auxílio de cartazes } \\
\text { expositivos }\end{array}$ \\
\hline $\begin{array}{l}\text { Novembro } \\
\quad(2019)\end{array}$ & $\begin{array}{lr}\text { Câncer de } & \text { próstata: } \\
\text { prevenção } & \mathrm{e} \\
\text { diagnóstico } & \\
\end{array}$ & $\begin{array}{l}\text { Unidade de } \\
\text { Saúde }\end{array}$ & $\begin{array}{l}\text { Adulto/idoso } \\
\text { (homens) }\end{array}$ & $\begin{array}{l}1 \text { hora e } 30 \\
\text { minutos }\end{array}$ & $\begin{array}{l}\text { Roda de conversa com bate-papo } \\
\text { dinâmico }\end{array}$ \\
\hline $\begin{array}{l}\text { Dezembro } \\
(\mathbf{2 0 1 9 )}\end{array}$ & HIV: como se proteger & $\begin{array}{l}\text { Unidade de } \\
\text { Saúde }\end{array}$ & $\begin{array}{l}\text { Adolescentes } \\
\text { /Adulto/idoso }\end{array}$ & $\begin{array}{l}1 \text { hora e } 30 \\
\text { minutos }\end{array}$ & Palestra (uso de cartazes) \\
\hline $\begin{array}{l}\text { Janeiro } \\
(2020)\end{array}$ & $\begin{array}{ll}\text { Primeiros } & \text { socorros } \\
\text { para crianças } & \end{array}$ & $\begin{array}{l}\text { Escola } \\
\text { Municipal }\end{array}$ & Crianças & 2 horas & $\begin{array}{l}\text { Roda de conversa com utilização de } \\
\text { peça teatral sobre primeiros } \\
\text { socorros. }\end{array}$ \\
\hline $\begin{array}{l}\text { Fevereiro } \\
(\mathbf{2 0 2 0})\end{array}$ & $\begin{array}{l}\text { Gravidez na } \\
\text { adolescência: educação } \\
\text { sexual }\end{array}$ & $\begin{array}{l}\text { Escola } \\
\text { Estadual }\end{array}$ & Adolescentes & 2 horas & $\begin{array}{l}\text { Bate-papo dinâmico com material } \\
\text { expositivo (slide) }\end{array}$ \\
\hline $\begin{array}{l}\text { Março } \\
(\mathbf{2 0 2 0})\end{array}$ & Higienização corporal & $\begin{array}{l}\text { Escola } \\
\text { Municipal }\end{array}$ & Crianças & 2 horas & $\begin{array}{l}\text { Roda de conversa com utilização de } \\
\text { peça teatral. }\end{array}$ \\
\hline $\begin{array}{l}\text { Maio } \\
(\mathbf{2 0 2 0})\end{array}$ & $\begin{array}{l}\text { Como anda a saúde } \\
\text { mental? }\end{array}$ & $\begin{array}{l}\text { Unidade de } \\
\text { Saúde }\end{array}$ & Adulto/idoso & $\begin{array}{l}1 \text { hora e } 30 \\
\text { minutos }\end{array}$ & $\begin{array}{l}\text { Roda de conversa com bate-papo } \\
\text { dinâmico }\end{array}$ \\
\hline $\begin{array}{l}\text { junho } \\
(2020)\end{array}$ & $\begin{array}{l}\text { Infecções sexualmente } \\
\text { transmissíveis (IST) }\end{array}$ & $\begin{array}{l}\text { Unidade de } \\
\text { Saúde }\end{array}$ & $\begin{array}{l}\text { Adolescentes } \\
\text { Adulto/idoso }\end{array}$ & $\begin{array}{l}1 \text { hora e } 30 \\
\text { minutos }\end{array}$ & $\begin{array}{l}\text { Roda de conversa com bate-papo } \\
\text { dinâmico com auxílio de cartazes }\end{array}$ \\
\hline
\end{tabular}

Fonte: Autores (2021).

Todas as ações foram desenvolvidas com recursos metodológico didático, lúdico e interativo, enfatizando o uso de metodologias ativas, escuta qualificada com acolhimento e encaminhamentos a partir das demandas existentes. Salienta-se que 
as temáticas foram trabalhadas respeitando a faixa etária de cada grupo, assim como as características socioeconômicas, culturais e ambientais dos protagonistas envolvidos no processo de educação em saúde. Neste sentido, durante às ações, objetivou-se disseminar informações e orientações buscando tornar o público sensibilizado a possuir maior controle e conhecimento acerca dos diferentes fatores que podem afetar a saúde, bem como, a aquisição de condutas e comportamentos saudáveis para a promoção à saúde e que diretamente aplicados ofertem resultados positivos na manutenção de uma vida saudável.

A utilização do jogo lúdico foi trabalhada pelas acadêmicas a partir da divisão do público-alvo em 4 (quatro) grupos, sendo selecionado apenas um representante de cada grupo e entregando a este uma placa contendo de um lado a palavra "mito" e do outro lado a palavra "verdade". O jogo ocorreu após a explanação do conteúdo como meio de avaliação dos assuntos abordados em que as acadêmicas lançavam afirmativas e após 60 segundos os participantes teriam que responder utilizando a placa se aquela frase correspondia a um mito ou verdade. Ao final do jogo foi distribuído brindes como forma de agradecimento.

Para a população adulta/idosa as ações de atenção à saúde e adesão ao autocuidado sucederam por meio de palestras, rodas de conversas firmando o diálogo e a troca de conhecimentos entre os envolvidos. Propondo uma melhor explanação sobre diversas temáticas voltadas sobre alimentação, prática de exercícios físicos, cuidados importantes para o portador de Diabetes Mellitus (DM) e Hipertensão Arterial Sistêmica (HAS) e entre outros. Assim, mediando orientações, condutas e práticas saudáveis que poderiam ser incorporadas no dia a dia de acordo com as condições socioeconômicas, tornando o indivíduo a figura central do próprio processo do cuidado.

As ações do projeto de extensão sobre os principais tipos de câncer que acometem a população adulto/idosa como câncer de mama, câncer de colo de útero e câncer de próstata foram realizadas por meio de cartazes informativos, dinâmicas e rodas de conversas, que possibilitaram também grandes aprendizados tanto para os acadêmicos como para a população.

\section{Resultados e Discussão}

Durante a realização do projeto diversas temáticas foram abordadas para a população visando a sensibilização desta frente ao autocuidado, bem como dá visibilidade a Enfermagem enquanto profissão integrante do processo saúde-doença (Souza et al., 2019; Gonçalves et al., 2018). Entre as principais temáticas apresentadas para cada público-alvo foram discutidas sobre primeiros socorros, alimentação saudável, Infecção Sexualmente Transmissível (ISTs), educação sexual, puberdade, citologia, câncer de mama, câncer de colo de útero, hipertensão arterial, diabetes mellitus e câncer de próstata. A partir dessas ações os acadêmicos atuaram como agentes promotores de saúde proporcionando ao público um cuidado embasado em conhecimentos científicos alinhados no acolhimento e atenção à saúde.

No decorrer da realização das práticas educativas do projeto com foco na promoção em saúde, os acadêmicos de enfermagem planejaram e implementaram diversas estratégias conforme o público-alvo e a necessidade existente, por exemplo em uma das ações desenvolvidas para crianças foi abordado sobre primeiros socorros, um vez que tal assunto não era discutido dentro do contexto escolar, com a utilização de materiais lúdicos como folder e fantoches confeccionados pelos acadêmicos e apresentação de uma peça de teatro foram mediadas orientações para crianças de como evitar situações que coloquem em risco a saúde como por exemplo afogamento, queimaduras, engasgo e como agir diante da ocorrência das mesmas.

Ainda no espaço escolar, direcionando as ações para o público adolescente, as atividades do projeto proporcionaram informações e orientações sobre as ISTs e a educação sexual, através de uma abordagem acolhedora e motivadora utilizando jogo lúdico e disposição de material ilustrativo, evidenciando a interação e participação ativa dos adolescentes, bem como a exposição de conhecimentos prévios, com ressalvas a mitos e verdades sobre a puberdade e o uso de anticoncepcionais. Freitas e Paula (2016) destacam que a realização dessas ações permite ao acadêmico aprimorar suas habilidades e aprendizagens, além 
de fazer uso dos conhecimentos científicos em situações intrínsecas à prática real.

Em destaque ao jogo lúdico, esse oportunizou maior interação entre os envolvidos assim como o processo de aprendizagem, os participantes envolvidos discutiam as respostas, favorecendo a troca de conhecimentos entre eles e junto as acadêmicas. Os participantes se divertiam com as respostas enquanto aprendiam sobre os temas abordados. Para os acadêmicos essa prática despertou a criatividade e o pensamento crítico-reflexivo com o envolvimento e a interação dos participantes.

É interessante destacar também a importância da mediação de informações corretas que são concretizadas nas atividades extensionistas pelos acadêmicos por meio da comunicação eficaz adequando a uma linguagem acessível para o público-alvo. Essas vivências assumem um papel importante na construção do saber do acadêmico, uma vez que o faz utilizar ferramentas de investigação científica. Neste cenário, Dominguez, Barros, Freire, Silva e Cardoso (2021) e Arruda-Barbos (2019), enfatizam que a utilização dessas ferramentas impulsiona o acadêmico a desenvolver o seu raciocínio investigativo, além de uma prática habitual pela pesquisa, buscando assim por meio de evidências científicas o cuidar qualificado.

Essa vivência viabilizou ao público, por meio dos discursos dos acadêmicos, o compartilhamento de informações de temáticas corriqueiramente abordadas, mas que desencadeiam grandes dúvidas principalmente em grupos que possuem dificuldade de acesso a informações. É importante destacar que o enfermeiro atua em diversas situações das quais muitas irão exigir do mesmo um preparo profissional e técnico diante de cenários que afetam a sociedade. Para o acadêmico essa experiência ainda na graduação influencia positivamente sua formação, pois permite a este a capacidade de lidar com diferentes grupos buscando a resolutividade dos problemas e respeitando a singularidade de cada um (Daltro \& Faria, 2019; Janini et al., 2015, Tristão \& Santos, 2015).

Observa-se que o emprego dessas ferramentas permitiu maior interação entre os participantes e consequentemente a criação de um vínculo. Cabe aqui ressaltar que, as atividades educativas de promoção à saúde permitiram a ação partilhada, estimulação do diálogo como troca de conhecimento, reflexão, escuta ativa, e primordialmente o acolhimento como forma indispensável de aproximação com o público, com isso os acadêmicos puderam visualizar o feedback positivo.

Rios et al. (2019) e Santos, Rocha e Passaglio (2016) abordam que as extensões em sua magnitude representam uma relevante construção de conhecimento e aprimoramento de práticas, assim, cabe ressaltar que os acadêmicos vivenciaram experiências consideradas pertinentes e indispensáveis no processo de formação, pois a extensão consegue em sua totalidade atender as necessidades não só da população que recebe a assistência, mas principalmente para o acadêmico que desenvolve habilidades atuando como multiplicador de conhecimentos científicos.

Cabe aqui ressaltar que o desenvolvimento e a estimulação do fortalecimento dessas práticas educativas, traz consigo uma gama de benefícios tanto para o bem-estar da população como para aquisição de habilidades e competências para os extensionistas, pois possibilita a esses experiências e vivências prático-teóricas, a formação de um olhar crítico e holístico, escuta qualificada, planejamento de intervenções de acordo com as necessidades sociais encontradas, além de uma postura profissional frente a área escolhida.

Nesta perspectiva, Costa et al. (2020) e Oliveira e Almeida Júnior et al. (2016), afirmam que é importante que os acadêmicos possam participar de atividades/projetos que permitam a experiência com situações reais de trabalho dentro da área de formação, possibilitando a atuação e aplicação na prática do que foi aprendido na teoria e com isso potencializar os conhecimentos e aprendizagens fortificando a formação acadêmica. Para a Enfermagem, as atividades extensionistas representam uma importante ferramenta de construção e aprimoramento de conhecimentos, além de possibilitar aos acadêmicos autonomia, pensamento crítico e reflexivo para resolução situações/problemas reais que fazem parte do trabalho do enfermeiro como reforça Silva et al. (2019) e Moraes, Guariente, Garanhani e Carvalho (2018).

Nesta perspectiva os acadêmicos puderam perceber a amplitude que representa a atuação do enfermeiro dentro dos espaços sociais, além das atribuições deste profissional no que diz respeito a prática da promoção de saúde para crianças nas 
escolas a partir de ações educativas, dinâmicas e lúdicas. Essas situações possibilitam verificar a relevância da incorporação de conhecimentos sobre a promoção da saúde a partir de vivências e atuações reais dentro dos currículos de Enfermagem, pois ensejam a formação de enfermeiros capazes de atuar em diferentes espaços e públicos e com a utilização de diversas estratégias objetivando uma assistência transdisciplinar, integral e significativa e não direcionada ao modelo biomédico como aborda Moraes et al. (2018) e Costa et al. (2015).

$\mathrm{Na}$ graduação de Enfermagem é fundamental que os acadêmicos possam conciliar a teoria com a prática, sendo indispensável o contato precoce com a população para que estes venham adquirir habilidades e aprimorar seus conhecimentos, diante disso as atividades de extensão possibilitam essa aproximação à medida que permitem que o acadêmico coloque na prática o que foi aprendido na teoria (Santos et al., 2016). Neste sentido, o projeto de extensão - PROES cujas ações estavam direcionadas na promoção em saúde da população por meio de ferramentas educativas possibilitou a disseminação de conhecimentos e potencializadores de autocuidado tornando o indivíduo figura central na atenção a sua saúde.

Concomitantemente, para os acadêmicos de enfermagem, o projeto permitiu o desenvolvimento de aptidões teóricoprático no que diz respeito a atuação de enfermagem frente ao público, identificando as necessidades e implementando diversas estratégias de promoção em saúde, embasando assim a construção de uma postura profissional ética, competente e humanizada. Ramos, Araruna, Lima, Santana e Tanaka (2018) evidenciam que a enfermagem é uma das áreas que por possuir maior contato com a população tem maior facilidade em promover à saúde sendo fundamental que este profissional vivencie situações ainda na graduação para que desenvolva habilidades e competências frente a área escolhida.

Por meio da utilização de diferentes espaços e grupos sociais, as atividades educativas desenvolvidas pelo PROES, impulsionaram a visão extra acadêmica dos graduandos frente a sua atuação na comunidade como elemento chave para produção de melhores condições de vida e consequentemente a diminuição da probabilidade do adoecimento populacional, além de contribuir positivamente na formação dos acadêmicos em oportunizar a atuação em situações reais que fazem parte do trabalho do enfermeiro enquanto agente mediador da promoção em saúde. Santos et al. (2016), apontam que na relação graduação-extensão, predomina a produção de aprendizagem teórico e prático que podem contribuir com o crescimento acadêmico ao mesmo tempo que traz benefícios à população.

Como fator limitante para a realização das oficinas, em março de 2020 com o agravamento da pandemia pelo novo coronavírus e a instituição de decretos estaduais e municipais que proibiam aglomerações houve dificuldade de contato com a população, diminuindo a quantidade de ações realizadas, principalmente em ambientes escolares. Foi necessário adequar o quantitativo de pessoas, para respeitar o distanciamento social.

\section{Conclusão}

A experiência da extensão universitária tem sido relatada neste contexto como uma ferramenta indispensável no processo de formação do enfermeiro, haja visto que fica evidente as contribuições proporcionadas às acadêmicas durante a realização das atividades para diferentes públicos e com o emprego de diversas estratégias educativas visando a promoção da saúde. Ao mesmo tempo, observa-se a importância da atuação dos graduandos de Enfermagem em situações reais favorecendo o contato precoce com a população e consequentemente a aquisição de habilidades e competências significativas para a futura prática profissional.

Dando ênfase as vivências experienciadas pelas discentes neste processo verificou-se a ligação entre a teoria e a prática, potencializando o ensino aprendido em sala de aula, assim como a busca por mais conhecimento por meio das atividades de pesquisa, possibilitando a interação entre a tríade pesquisa-ensino-extensão. Ademais, a partir da implementação e combinação de estratégias e práticas simples, as acadêmicas puderam disseminar informações e orientações sobre temáticas pertinentes adequando-as com a realidade existente de cada indivíduo/grupo social, trazendo benefícios não só para a 
população como também para as discentes por meio do desenvolvimento de aptidão e da assistência de Enfermagem.

Em contrapartida nota-se o déficit de atividades extra-acadêmicas, em especial das atividades de extensão, por corresponderem práticas alternativas frente ao ensino universitário, levando muitos acadêmicos de Enfermagem a terminarem sua graduação sem participar dessa experiência tão enriquecedora para sua formação, ou quando participam não compartilham através dos meios científicos. Observou-se limitação de pesquisas que fundamentassem a importância dessa prática na formação do enfermeiro.

Neste contexto, recomenda-se que durante a graduação de Enfermagem os discentes possam ser estimulados a criar/participar de projeto de extensões, assim como partilhar as vivências adquiridas neste processo por meio da produção e publicação de pesquisa envolvendo o cenário experienciado, possibilitando a disseminação de conhecimentos e práticas inovadoras dentro campo da Enfermagem e consequentemente reformulando atividades tradicionais e verticais em condutas éticas, humanizadas e profissional adquiridas através de uma formação embasada em estratégias extra-acadêmicas.

\section{Referências}

Arruda-Barbosa, L. de, Sales, M. C., Souza, I. L. L. de, Gondim-Sales, A. F., Silva, G. C. N. \& Lima-Júnior, M. M. (2019). Extensão como ferramenta de aproximação da universidade com o ensino médio. Cadernos de Pesquisa, 49(174), 316-327.https://doi.org/10.1590/198053146465

Backes, D. S., Haag, B. K., Vasconcelos, J., Dalcin, C. B., Backes, M. T. S. \& Lomba, L. (2018). Acadêmicos de enfermagem na comunidade: estratégia empreendedora e propositora de mudanças. Revista Brasileira de Enfermagem, 71(4), 1799-1804. https://doi.org/10.1590/0034-7167-2017-0382

Costa, D. V. S., Bezerra, K. C., Alves, N. P., Façanha, M. C., Evaristo, A. C. \& Luna, M. C. S. (2015). Extensão universitária na promoção da saúde infantil: analisando estratégias educativas. Rev. Ciênc. Ext. 11 (1), 25-31. http://www.repositorio.ufc.br/handle/riufc/15257.

Costa D. A. C., Cabral K. B, Teixeira C. C., Rosa R. R., Mendes J. L. L. \& Cabral, F. D. (2020). Enfermagem e a Educação em Saúde. Rev Cient Esc Estadual Saúde Pública Goiás “Candido Santiago”.6(3):e6000012.

Daltro, M. R. \& Faria, A. A. de. (2019). Relato de experiência: Uma narrativa científica na pós-modernidade. Estudos e Pesquisas em Psicologia, Rio de Janeiro, 19 (1), 223-237. https://www.e-publicacoes.uerj.br/index.php/revispsi/article/view/43015/29726.

Dominguez, R., Barros, Ê., Freire, A., Silva, S., \& Cardoso, L. (2021). Enfermagem oncológica: integração universidade-comunidade no processo de ensinoaprendizagem. Revista de Enfermagem UFPE online, 15(1). https://doi.org/10.5205/1981-8963.2021.244374

Ferreira, P. B., Suriano, M. L. F. \& Domenico, E. B. L., (2018) Contribuição da Extensão Universitária na formação de graduandos em Enfermagem. Rev. Ciênc. Ext. 14 (3), 31-49. Disponível em: https://core.ac.uk/download/pdf/300077182.pdf.

Freitas, T., Paula, C., Zanon, B., Meirelles, F., Welleir, T., \& Padoin, S. (2016). Contribuições da extensão universitária na formação de acadêmicos de enfermagem. Revista de Enfermagem da UFSM, 6(3), 307 - 316. https://doi.org/10.5902/2179769219966

Gonçalves, E. R., Ferrareze, M. V., Santos, J. T. T. S., Pitta, N. C., Pereira, R. M. de P. \& Fernandes, A. P. M., (2018) Rev Min Enferm. 22, e-1133, http://www.dx.doi.org/10.5935/1415-2762.20180062

Janini, J. P., Bessler, D., Vargas, A. B. de. (2015). Educação em saúde e promoção da saúde: impacto na qualidade de vida do idoso. Saúde em Debate, 39 (105), 480-490. https://doi.org/10.1590/0103-110420151050002015

Lima, M. M. de., Machado, M. L., Costa, R., Canever, B. Pina, J.C. \& Alves, I. F. B. de O. (2018). Contribuição da extensão em um grupo de gestantes e casais grávidos para a formação do enfermeiro. Escola Anna Nery, 22(4), e20170367.https://doi.org/10.1590/2177-9465-ean-2017-0367

Mendes, R., Fernandez, J. C. A., \& Sacardo, D. P. (2016). Promoção da saúde e participação: abordagens e indagações. Saúde em Debate, 40(108), 190-203. https://doi.org/10.1590/0103-1104-20161080016

Moraes, A., Guariente, M. H. D. de M., Garanhani, M. L., Carvalho, B. G. de. (2018). A formação do enfermeiro em pesquisa na graduação: percepções docentes. Revista Brasileira de Enfermagem, 71(Suppl. 4), 1556-1563. https://doi.org/10.1590/0034-7167-2017-0511

Oliveira, F. L. B. de, \& Almeida Júnior, J. J. de. (2016). Extensão universitária: contribuições na formação de discentes de Enfermagem. Revista Brasileira De Pesquisa Em Saúde/Brazilian Journal of Health Research, 17(1), 19-24. https://www.periodicos.ufes.br/rbps/article/view/12445

Palheta, A. M. da S., Cecagno, D., Marques, V. de A., Biana, C. B., Braga, L. R., Cecagno, S., Moura, P. M. M. \& Porto, A. R. (2020). Formação do enfermeiro por meio de metodologias ativas de ensino e aprendizado: influências no exercício profissional. Interface - Comunicação, Saúde, Educação, 24, e190368. https://doi.org/10.1590/interface.190368

Ramos, C. F. V., Araruna, R. da C., Lima, C. M. F. de, Santana, C. L. A. de \& Tanaka, L. H., (2018). Práticas educativas: pesquisa-ação com enfermeiros da Estratégia de Saúde da Família. Revista Brasileira de Enfermagem, 71(3), 1144-1151. https://doi.org/10.1590/0034-7167-2017-0284

Rios, D. R. da S., Sousa, D. A. B. de \& Caputo, M. C. (2019). Diálogos interprofissionais e interdisciplinares na prática extensionista: o caminho para a inserção do conceito ampliado de saúde na formação acadêmica. Interface - Comunicação, Saúde, Educação, 23, e180080. https://doi.org/10.1590/interface. 180080 
Research, Society and Development, v. 10, n. 7, e57310716915, 2021

(CC BY 4.0) | ISSN 2525-3409 | DOI: http://dx.doi.org/10.33448/rsd-v10i7.16915

Santos, J. H. de S., Rocha, B. F. \& Passaglio; K. T. (2016). Extensão Universitária e formação no Ensino Superior. Revista Brasileira de Extensão Universitária, 7 (1), 23-28. Disponível em: https://periodicos.uffs.edu.br/index.php/RBEU/article/view/3087/pdf

Silva, A. B., Sousa, S. C. S., Chaves, A. C. F., Sousa, S. G. da C. Andrade, T. M.de. \& Rocha Filho, D.R. (2019). Importância da Extensão Universitária na Formação Profissional: Projeto Canudos. Revista de Enfermagem UFPE online, 13. https://doi.org/10.5205/1981-8963.2019.242189.

Souza, L. E. P. F. de, Paim, J. S., Teixeira, C. F., Bahia, L., Guimarães, R., Almeida-Filho, N. de, Machado, C. V., Campos, G. W. \& Azevedo-e-Silva, G. (2019). Os desafios atuais da luta pelo direito universal à saúde no Brasil. Ciência \& Saúde Coletiva, 24(8). https://doi.org/10.1590/141381232018248.34462018

Tristão, F. R. \& Santos, S. M. A. dos, (2015). Atenção ao familiar cuidador de idoso com doença de alzheimer: uma atividade de extensão universitária. Texto contexto - enferm., 24 (4), 1175-1180. https://doi.org/10.1590/0104-0707201500003060014 